\title{
Crises e transformações do capitalismo - o diagnóstico de época de Friedrich Pollock*
}

\author{
Crises and transformations of capitalism - Friedrich Pollock's \\ epochal diagnosis
}

Fernando Rugitsky

rugitsky@gmail.com

(Universidade de São Paulo, São Paulo, Brasil)

\begin{abstract}
Resumo: 0 artigo aborda os deslocamentos da interpretação de Friedrich Pollock sobre as tendências inscritas de transformação do capitalismo após a crise de 1929 e sobre as perspectivas para a emancipação. O foco recai em dois artigos do início dos anos 1930 e no famoso "Capitalismo de Estado: possibilidades e limites", de 1941. Sua interpretação é lida no contexto da história do período e do debate contemporâneo ocorrido no Instituto de Pesquisa Social de Frankfurt. 0 objetivo é aprofundar a compreensão acerca da interpretação contida no artigo de 1941, indicando semelhanças e diferenças com aquelas expostas no início dos anos 1930.
\end{abstract}

Palavras-chave: Pollock; teoria crítica; relações de produção; forças produtivas; capitalismo de Estado.

\begin{abstract}
The paper examines the shifts in Friedrich Pollock's interpretation about the inherent tendencies of transformation of capitalism after the crisis of 1929 and about the prospects for emancipation. The focus lies on two papers from the early 1930s and on the famous "State capitalism: its possibilities and limitations," from 1941. His interpretation is read in the historical context of the period and in light of the contemporaneous debate within Frankfurt's Institute for Social Research. The goal is to deepen the understanding about the interpretation provided in the 1941 paper, indicating similarities and differences with those formulated in the early 1930 s.
\end{abstract}

Keywords: Pollock; critical theory; relations of production; productive forces; state capitalism.

DOI: http://dx.doi.org/10.11606/issn.2318-9800.v22i2p111-134

\section{Apresentação}

Recentemente, o capitalismo entrou mais uma vez em crise. Muitos podem se perguntar por que o modo de produção se sujeita recorrentemente a esses abalos. Mas surpreendente mesmo é o fato de que uma economia dependente, em maior ou menor grau, da ação descoordenada dos proprietários dos meios de produção seja relativamente estável ao longo do tempo. Verifica-se historicamente que a coordenação social, relativamente descentralizada, da produção e da distribuição ocorre de forma notavelmente equilibrada, até que a reprodução do sistema

\footnotetext{
* Muitas pessoas discutiram comigo a obra de Friedrich Pollock nos últimos anos e contribuíram, assim, para que eu a melhor compreendesse. Devo um agradecimento especial àqueles que compareceram aos três Cursos livres de Teoria Critica, em São Paulo, Curitiba e Campinas, e ao Curso aberto Direito e Teoria Crítica. Agradeço também a Marcos Nobre, interlocutor constante.
} 
econômico seja novamente colocada em questão por uma crise. Nas palavras de John Maynard Keynes, "é uma característica marcante do sistema econômico em que vivemos que, embora ele esteja sujeito a acentuadas flutuações dos níveis de produto e emprego, ele não seja violentamente instável” (Keynes, 1936/1997, p.249). Dessa maneira, qualquer análise rigorosa do capitalismo deve partir desta tensão estrutural entre crise e reprodução. ${ }^{1}$

A teoria crítica, a fim de levar adiante o legado de Karl Marx, propõe-se compreender o capitalismo a partir da formulação de diagnósticos de época. Tratase de apreender o que há de específico no capitalismo de cada período, abordando a forma que assume a dominação social e as perspectivas que estão abertas para a emancipação. Tal tarefa depende, em cada época, da resposta à questão sobre o que representa continuidade e o que representa descontinuidade em relação ao padrão precedente. Afinal, o capitalismo é um modo de produção dinâmico, em contínua transformação, mas, ao mesmo tempo, apresenta características constantes, que permitem inclusive que se continue a referir a ele por "capitalismo". Todo diagnóstico de época requer, então, que se aborde também a tensão entre continuidade e descontinuidade. ${ }^{2}$

Friedrich Pollock (1894-1970) é um exemplo raro de um autor que buscou diagnosticar o capitalismo de sua época levando ambas as tensões a sério. Escrevendo ao longo da década de 1930, especialmente, e participando do ambiente interdisciplinar do Instituto de Pesquisa Social de Frankfurt, ele foi um observador privilegiado de um período em que a economia capitalista passou por profundas transformações. Seus textos mostram um cuidado para analisar os detalhes do processo histórico em curso, sem deixar de lado, contudo, o significado dos acontecimentos em uma perspectiva histórica mais longa. Pollock abordou explicitamente as questões deixadas em aberto pela tradição do pensamento marxista que o precedeu, mas, ao mesmo tempo, não menosprezou o potencial de uma apropriação crítica da teoria econômica convencional de sua época.

Abordei em outro trabalho (2008) a posição que a obra de Pollock ocupa em

1 No mesmo sentido, ver Anwar Shaikh (1978, p.219): "A questão verdadeiramente difícil sobre tal sociedade [capitalista] não é por que ela colapsa, mas por que ela continua a funcionar. Dessa perspectiva, é importante notar que qualquer explicação sobre como o capitalismo se reproduz é, ao mesmo tempo (implícita ou explicitamente), uma resposta à questão de como e por que a nãoreprodução ocorre, e vice-versa: em outras palavras, a análise da reprodução e a análise da crise são inseparáveis".

2 A crítica realizada por Robert Brenner e Mark Glick aos teóricos regulacionistas exemplifica as implicações dessa tensão entre continuidade e descontinuidade. Os regulacionistas, partindo da tradição marxista, propõem uma periodização para o capitalismo, de forma que cada período apresentaria um regime de acumulação e um modo de regulação específicos. No entanto, Brenner e Glick argumentam que a ênfase nas diferenças institucionais obscurece as continuidades históricas, determinadas pelas relações sociais de propriedade capitalistas. Segundo eles, uma análise histórica cuidadosa permitiria dissolver as demarcações propostas pelos regulacionistas. Ver Brenner e Glick (1991). 
relação ao marxismo da primeira metade do século XX. Basta mencionar aqui que ele recupera as questões deixadas pelas teorias da crise, particularmente a partir dos diagnósticos distintos da estabilização e da desestabilização do capitalismo (que se consolidaram como a divergência entre a Segunda e a Terceira Internacional), buscando atualizá-las e reformulá-las face à crise de 1929 e aos desdobramentos posteriores. O objetivo deste capítulo será reconstruir a formulação do seu diagnóstico de época, ressaltando os deslocamentos pelos quais suas análises passaram em paralelo aos acontecimentos do período. Vale, por fim, ressalvar que os seus trabalhos posteriores à Segunda Guerra Mundial, particularmente o livro sobre a automação (1956/1957), não serão abordados. Reavaliar esses textos, a partir do diagnóstico do capitalismo de Estado, pode ser um ponto de partida interessante para discutir a atualidade do pensamento de Pollock. ${ }^{3}$

\section{Forças produtivas e relações de produção em ponto de ruptura}

Ainda que as crises sejam um fenômeno recorrente nas economias capitalistas, sempre que elas ocorrem multiplicam-se as explicações que as atribuem a fatores específicos, como choques inesperados ou ganância desmedida de alguns grupos. No jargão dos economistas, são explicações que localizam a causa das crises em fatores "exógenos" ao sistema capitalista, evitando que a sua estrutura seja responsabilizada pela conjuntura desfavorável. Esse recurso é essencial para aqueles que pretendem defender que o capitalismo é um modo de produção estável, isto é, cujo funcionamento não leva necessariamente a crises. Elas seriam sempre provocadas por perturbações estranhas ao sistema e não há nada que indique que tais perturbações devam voltar a ocorrer. Assim, passada esta crise (qualquer que ela seja), não há porque supor que a nova situação de estabilidade não possa se reproduzir indefinidamente.

Não foi diferente em 1929. Em um artigo publicado em 1933, chamado “Observações sobre a crise econômica”, Pollock afirmou:

Ainda hoje, circula frequentemente a opinião segundo a qual tanto a catástrofe econômica americana quanto a crise mundial são produtos de fatores "exógenos". (...) Explicações desse gênero, contudo, não são satisfatórias, porque não são capazes de explicar aquela típica regularidade que a análise dos ciclos, apesar da crescente

3 Os trabalhos de Pollock discutidos neste capítulo foram publicados, originariamente, em alemão e em inglês. Infelizmente, ainda não há tradução de nenhum deles para o português. A única tradução disponível é para o italiano, realizada por Giacomo Marramao, para a coletânea que organizou em 1973. Além disso, ainda há poucos trabalhos que se dedicaram a analisar o pensamento de Pollock. Destacam-se, entre eles, o trabalho pioneiro de Marramao (1973/1990) e as análises mais recentes de Carlo Campani (1992), Moishe Postone (1993/2003), Harry Dahms (2000), Gustavo Pedroso (2009), John Abromeit (2011), Tobias ten Brink (2015) e Manfred Gangl (2016). A tendência de vários desses trabalhos é recusar o diagnóstico de Pollock em virtude de seu distanciamento do diagnóstico de Marx. Assim, Marramao, por exemplo, recorre a formulações marxistas mais ortodoxas, particularmente a Henryk Grossman, colega de Pollock no Instituto de Pesquisa Social. Já Postone propõe uma leitura mais próxima da própria obra de Marx, a partir especialmente das pistas que os Grundrisse fornecem para a compreensão de $O$ capital. 
diferenciação, sempre enfatizou (Pollock, 1933/1973, pp.136-137). ${ }^{4}$

Nos seus dois artigos que analisam a grande depressão, iniciada em 1929, ele fez questão de ressaltar que ela era uma crise capitalista "normal”, provocada pelas mesmas causas que levaram a todas as demais crises, nacionais e internacionais, ocorridas desde o início do século XIX (Pollock, 1932/1973, pp.88, 93; 1933/1973, pp.136-137). Além disso, o mecanismo que ligou os diversos efeitos da crise também foi típico: redução da produção, demissões, queda das vendas, queda dos preços, contração do crédito, inadimplência, crise de confiança e falências (Pollock, 1933/1973, pp.137).

Isso não o impediu, no entanto, de ressaltar a gravidade do processo então em curso. Após mencionar um trecho de um relatório com dados sobre a crise, Pollock comenta que ele soa "como um boletim militar de uma guerra perdida" (Pollock, 1932/1973, p.86). Segundo ele, a crise de 1929 superou todas as anteriores em termos de gravidade, duração e difusão (tanto geográfica, quanto no que diz respeito aos setores da economia) (Pollock, 1933/1973, pp.137-138). A depressão provocou uma redução da produção e um aumento do desemprego sem precedentes e está evidentemente por trás das convulsões políticas e sociais que marcaram a década de 1930, culminando na Segunda Guerra Mundial. Por mais significativas que sejam, as estatísticas da crise não conseguem transmitir adequadamente a dimensão desse processo histórico único. ${ }^{5}$

Atento aos detalhes da crise, ele se propõe a explicar o que há de específico nela, que determinou a profundidade do abalo e retardou a recuperação das economias. Três grupos de fatores são ressaltados. Primeiro, as perturbações políticas que remontam à Primeira Guerra Mundial e à Conferência de Paz que a encerrou. Segundo, a crise agrícola relacionada à transformação da técnica de produção no campo. $E$, por fim, transformações estruturais do capitalismo, relacionadas essencialmente à concentração do capital, que impediam o funcionamento normal do mecanismo do mercado (Pollock, 1932/1973, pp.88-93; 1933/1973, pp.139-148).

Os dois primeiros grupos de fatores retiraram a elasticidade da economia mundial, ampliando os efeitos da queda conjuntural "normal”. As principais fontes de instabilidades, relacionadas à guerra, eram as dívidas contraídas pelos países envolvidos no conflito e as reparações exigidas dos derrotados. Elas não apenas dificultaram a estabilização no começo da década de 1920, quando se buscou controlar os processos inflacionários em curso nas principais economias europeias e restabelecer

4 Todos os trechos citados de obras em línguas estrangeiras foram traduzidos por mim, salvo indicação contrária.

5 Uma das melhores narrativas sobre a grande depressão foi realizada por Charles P. Kindleberger (1986), ainda que ele, às vezes, atribua a erros de política econômica processos que, na realidade, resultam de impasses e conflitos político-sociais. 
o sistema monetário internacional, mas também resultaram na fragilidade do sistema de crédito internacional, que serviu de mecanismo de transmissão da crise. ${ }^{6}$ Além disso, Pollock ressalta também que a guerra destruiu a divisão internacional do trabalho que existia anteriormente, devido à industrialização de países até então predominantemente agrícolas. Desse modo, era difícil equilibrar os balanços de pagamentos, complicando-se ainda mais a estabilização das economias.

A crise agrícola, por outro lado, resultava da mecanização da agricultura. Já desde antes de 1929, esta transformação dos métodos produtivos havia levado a uma superprodução com consequente queda nos preços. Colocava-se, pois, em xeque a subsistência de parte da população rural. De acordo com Pollock, a coincidência da crise industrial com a crise agrícola, em 1929, foi particularmente grave porque reduziu as válvulas de escape da economia como um todo. Em crises anteriores, a relativa estabilidade da agricultura, em relação à indústria, amenizava o impacto da desaceleração econômica porque mantinha razoavelmente estável a renda de uma parte da população. Algo semelhante resulta da alteração da divisão internacional do trabalho. Com a industrialização de regiões relativamente retardatárias, o recurso à exportação de capital e à abertura de novos mercados, frequentemente utilizado em crises anteriores, torna-se mais limitado.

A ênfase maior da análise de Pollock recai, entretanto, no terceiro grupo de fatores. Eles se vinculam, fundamentalmente, à realização daquela tendência que Marx denominou de lei de concentração e centralização do capital. ${ }^{7}$ Desde o fim do século XIX, a formação dos grandes conglomerados, exemplarmente em torno da indústria siderúrgica e do transporte ferroviário, combinando atividades industriais e bancárias, era percebida como uma transformação decisiva do capitalismo. Segundo o historiador Eric J. Hobsbawm (1989, p.52), uma das principais características da economia anterior à Primeira Guerra Mundial foi "o crescimento de escala que levou os homens a distinguirem 'empresas' de 'grandes empresas'”. O período entreguerras apenas aprofundou essa tendência, com a inauguração da produção em massa na indústria automobilística. De acordo com Pollock, em 1927, 44 por cento do capital das cerca de 30 mil empresas dos Estados Unidos pertencia a apenas 200 delas. $\mathrm{Na}$ Alemanha, por sua vez, mais da metade do volume de investimento total foi realizado, em 1930, por apenas 189 das quase 11 mil sociedades anônimas (Pollock,

6 Segundo Karl Polanyi, "[u]ma sequência quase ininterrupta de crises cambiais ligou os indigentes Bálcãs aos afluentes Estados Unidos, através do cordão elástico do sistema internacional de crédito" (1944/2001, p.25). Logo após a Conferência de Paz de Versalhes, Keynes, que havia participado como representante do Tesouro britânico, denunciou os riscos que ela havia criado em um livro que o tornou famoso no mundo inteiro, As Consequências Econômicas da Paz. Ver Keynes (1919/2004, pp.47-298).

70 ponto de partida de Rudolf Hilferding, em sua tentativa de atualizar a obra de Marx, é também a realização da lei de concentração e centralização do capital. O capital financeiro (1910/1985), publicado em originariamente 1910, é um marco do pensamento marxista do início do século XX e sua influência sobre a obra de Pollock é clara. Ver, nesse sentido, Nobre (1998, pp.25-28). 
1932/1973, p.89).

Tal deslocamento de uma parcela significativa da produção para as grandes fábricas amplia enormemente a rigidez da economia. As grandes unidades econômicas não precisam se sujeitar ao preço determinado pelo "livre jogo das forças de mercado", mas determinam elas mesmas o preço de venda dos seus produtos. Além disso, os incentivos associados aos riscos dos empreendimentos econômicos deixam de operar quando o Estado é obrigado a ajudar as grandes empresas que passam por dificuldades, uma vez que, caso elas venham a falir, os efeitos deletérios sobre o nível de emprego e sobre a economia como um todo seriam excessivos. Tratase do argumento, que ganhou destaque nessa crise atual, segundo o qual algumas empresas são "grandes demais para quebrar" (too big to fail). O significado disso, segundo Pollock, é que na fase monopolista do capitalismo a apropriação privada dos lucros passa a conviver com a divisão social dos riscos. Ainda, a grande influência dos dirigentes dos grandes conglomerados sobre os governos permite que se isole os mercados nacionais, em seu benefício, do poder potencialmente regulador da concorrência estrangeira, através principalmente da proteção alfandegária. De forma geral, a autonomia relativa entre a economia e a política tornava-se gradualmente mais limitada.

O argumento de Pollock consiste em afirmar que todas essas transformações estruturais pelas quais passava o capitalismo criavam obstáculos para o funcionamento do mecanismo de mercado. A maior rigidez da economia, o papel desempenhado pelos crescentes "custos fixos" das empresas e a alteração na estrutura de incentivos representada pelas relações de produção retirava do capitalismo o seu automatismo, isto é, o seu mecanismo reequilibrador. A queda conjuntural ocorrida em 1929, então, atingiu uma economia com menor flexibilidade, devido a todos esses fatores, e cujo mecanismo de coordenação deixara de funcionar normalmente. Daí a profundidade da depressão e sua duração devastadora.

Os efeitos sociais da crise adquiriam um relevo especial quando confrontados com a imensa prosperidade que havia marcado a década de 1920, principalmente nos Estados Unidos. O otimismo característico da "era do jazz", dos chamados "roaring twenties", tinha se desfeito da noite para o dia. Era difícil de compreender como eram atingidos níveis alarmantes de desemprego e pobreza em um momento em que as possibilidades técnicas disponíveis à sociedade pareciam imensas. Vinha à tona, assim, o paradoxo da pobreza em meio à abundância ou, nas palavras de Pollock,

a estridente contradição entre o empobrecimento de estratos cada vez maiores da população e a falta de meios para a solução dos problemas mais urgentes da civilização, por um lado, e as possibilidades técnicas resultantes do revolucionamento dos métodos produtivos empregados na economia agrícola e do progresso explosivo da produtividade do trabalho industrial, por outro (Pollock, 1932/1973, p.87). 
Vinculando-se à tradição teórica inaugurada por Marx, Pollock afirma que esta contradição é na realidade uma característica do capitalismo. Segundo ele, a estrutura fundamental de todas as crises capitalistas é determinada pelo conflito entre as forças produtivas e as relações de produção (Pollock, 1933/1973, p.135). Não se trata de afirmar que as relações de produção constitutivas do capitalismo, a utilização do trabalho assalariado alheio pelos proprietários dos meios de produção, são inadequadas para o desenvolvimento das forças produtivas. Na verdade, desde o seu surgimento, o capitalismo desenvolveu enormemente as forças produtivas, ainda que nunca se tenha calculado adequadamente os custos envolvidos nos meios bárbaros empregados - que são chamados eufemisticamente de fricções, como ressalta Pollock (1932/1973, pp.93-94). No entanto, o próprio processo histórico da acumulação de capital leva a um conflito crescente entre as forças produtivas e as relações de produção, de modo que estas eventualmente tornam-se um obstáculo ao ulterior desenvolvimento daquelas. Na prática, tal conflito "se manifesta na contradição entre as possibilidades técnico-econômicas ilimitadas e o escopo limitado - tendencialmente mais arduamente realizável - da valorização do capital” (Pollock, 1933/1973, p.135; e, no mesmo sentido, idem, p.157).

A situação do capitalismo de sua época era, assim, interpretada por Pollock como um momento em que o conflito entre as forças produtivas e as relações de produção atingiam um grau particularmente agudo. E a grande depressão nada mais era do que um sintoma enfático desse conflito. Contudo, como se sabe, a tradição marxista previa que tal tensionamento culminasse em um desdobramento histórico determinado:

Uma das concepções fundamentais da teoria econômica marxiana é aquela segundo a qual um novo sistema econômico só pode ser estabelecido depois que os seus pressupostos econômicos e sociais já se constituíram, pelo menos em germe, sob a superfície do sistema precedente, e que as relações de produção se converteram em grilhões das forças produtivas (Pollock, 1932/1973, pp.98-99).

Toda a argumentação acima busca evidenciar justamente que as relações de produção se converteram em “grilhões das forças produtivas”. São tais relações, afinal, que limitam a utilização dos meios técnicos abundantes para a satisfação das necessidades sociais. Uma manifestação explícita dessa limitação, mencionada por Pollock, é o fato de que, na média dos ciclos econômicos, a produção efetiva é menor do que aquela permitida pela capacidade produtiva, resultando em capacidade ociosa.

Resta, então, analisar se os pressupostos econômicos e sociais de um novo sistema econômico já se constituíram e, naturalmente, analisar qual é esse novo sistema econômico. Em um artigo publicado em 1932, Pollock afirma que a única direção possível para a substituição do sistema econômico por um outro é 
a de uma reorganização planejada da economia (Pollock, 1932/1973, pp.95-96). Especificamente, ele concebe uma economia planejada como um sistema econômico em que a produção e a distribuição são reguladas centralizadamente através de um planejamento social (idem, p.97). Segundo ele, as dificuldades enfrentadas pelas economias capitalistas incentivaram a disseminação das discussões sobre planejamento econômico. E o fato de que a União Soviética, recorrendo a um planejamento econômico centralizado, não apenas não fracassou, como muitos previam, mas também logrou passar ilesa pela grande depressão incentivava ainda mais esse debate (idem, p.96). Pollock acompanhava de perto a literatura que surgia sobre o assunto.

Descrevendo vários desenvolvimentos recentes, observáveis tanto nos grandes países industriais quanto na economia mundial em seu conjunto, ele argumenta que os pressupostos econômicos para a reorganização planejada da economia já estavam constituídos (Pollock, 1932/1973, pp.99-101). Entre eles, destaca-se, por exemplo, a uniformização da direção científica das empresas, com o planejamento do progresso técnico e a adoção de métodos estatísticos de organização dos processos produtivos. Os aperfeiçoamentos das comunicações e as diversas medidas concebidas para o controle da economia de guerra também eram relevantes. Mas, na sua opinião, os pressupostos essenciais seriam o avanço da centralização do capital e a existência de uma reserva de produtividade disponível, que poderia ser aproveitada pelo órgão planejador. Como se pode perceber, "[a]quele mesmo desenvolvimento que se demonstra fatal para o 'funcionamento normal do mecanismo de mercado' cria um dos mais importantes pressupostos para a direção planejada do processo econômico" (idem, p.99).

Entretanto, ao contrário do que se poderia imaginar, a superação do conflito entre forças produtivas e relações de produção através de uma reorganização planejada da economia não é, para Pollock, equivalente a emancipação ou a socialismo. Ainda que ele afirme, no artigo de 1932, que “apenas uma reorganização planejada da economia estaria em condições de superar as dificuldades atuais e de transformar as forças econômicas, de poderes destrutivos e mortais, que são hoje, em poderes a serviço dos homens" (Pollock, 1932/1973, p.88), ele concebe dois tipos de economia planejada: capitalista ou socialista. Uma economia planejada capitalista seria baseada na propriedade privada dos meios de produção, enquanto a socialista seria caracterizada pela propriedade pública dos meios de produção (idem, 1932/1973, p.97). Além disso, ele ressalta que ainda não se sabe se os dois tipos de economia planejada podem alcançar os mesmos resultados.

A fim de compreender o sentido dessa posição, é necessário esclarecer o que os membros do Instituto de Pesquisa Social de Frankfurt achavam que estava em jogo no começo da década de 1930. Helmut Dubiel (1978/1985, pp.37-38) argumenta que, 
neste período, eles apostavam que a emancipação ocorreria através da abolição da propriedade privada dos meios de produção e da adoção do planejamento econômico. Mais do que isso, eles compreendiam a sua própria tarefa como uma contribuição neste sentido e, concretamente, organizaram uma pesquisa específica, no interior do instituto, sobre o tema do planejamento econômico. Conduzida por Kurt Mandelbaum e Gerhardt Meyer, os dois principais colaboradores de Pollock no instituto, a pesquisa foi realizada entre 1930 e 1934. Pollock manifesta explicitamente sua concordância com essa orientação na frase que encerra o seu artigo de 1932, em que ele diz que é "importante acompanhar as tendências que apontam na direção de uma economia planejada, considerando todas as possibilidades de sua realização e construindo uma teoria completa que possa servir de instrumento para uma política econômica futura" (Pollock, 1932/1973, p.108). ${ }^{8}$

Como, já em 1933, Hitler ascenderia ao poder e implantaria o regime nazista na Alemanha, bloqueando a possibilidade de qualquer emancipação, essa aposta pode parecer excessivamente otimista. No entanto, o seu contexto é a profunda indefinição política que caracterizava o início da década de 1930. Fazia pouco mais de dez anos que uma revolução socialista havia ocorrido na Rússia e, na Europa ocidental, os partidos socialdemocratas e comunistas tinham um poder eleitoral sem precedentes. Embora Pollock e seus colegas não se deslumbrassem com a experiência soviética, eles nutriam por ela uma simpatia cautelosa, no início da década de 1930, aguardando os próximos desenvolvimentos. É necessário lembrar que Pollock, convidado por David Ryazanov, que dirigia o Instituto Marx-Engels em Moscou, viajou para a Rússia durante as comemorações dos 10 anos da revolução, em 1927. Ele aproveitou essa ocasião, aliás, para escrever um longo estudo sobre a experiência soviética de planejamento, que foi publicado em $1929^{9}$. Somando-se a profunda crise de 1929 à experiência soviética e à força dos partidos socialistas e comunistas, fica claro que os rumos futuros do capitalismo estavam indefinidos e que não cabia excluir do horizonte a possibilidade de uma transformação emancipatória.

No entanto, a cautela de Pollock ao distinguir dois tipos possíveis de economia planejada já indica, de alguma maneira, suas incertezas em relação a essa avaliação. Antecipando o que será decisivo nos seus diagnósticos posteriores, ele já afirma, em 1932, “que esta crise pode ser superada por meios capitalistas" (Pollock, 1932/1973, p.94). E, um pouco adiante, completa: “[o]s elementos para a superação da crise econômica atual já estão, em larga medida, presentes” (idem, ibidem). Entretanto, ao discutir os pressupostos sociais e políticos para cada tipo de economia planejada, ele explicita a indefinição do período (idem, p.108). Segundo ele, os proprietários dos

8 Ver, também, sobre a importância da discussão sobre o planejamento no interior do instituto, Giacomo Marramao (1973/1990, pp.203-205).

9 Alguns trechos deste livro foram publicados na coletânea organizada por Giacomo Marramao. Ver Pollock (1929/1973). 
meios de produção não tolerariam uma economia planejada capitalista, porque ela os degradaria à condição de meros rentiers, dificultando a manutenção da sua posição social, uma vez que ela não estaria relacionada a nenhuma função específica. Por outro lado, Pollock já antecipa uma derrota dos trabalhadores, afirmando que uma economia planejada socialista é improvável porque os estratos sociais objetivamente interessados nela não dispõem de influência suficiente para subverter a atual ordem social. A conclusão do artigo assume, então, um tom de incerteza.

É revelador do ritmo acelerado das transformações históricas no período que, em um artigo publicado em 1933, apenas um ano depois, já possa ser identificado um deslocamento desse diagnóstico inicial. E, claramente, não se trata de uma mudança de opinião sem motivo, dado que o sentido do artigo de 1933 é precisamente atualizar o diagnóstico em face de dois desenvolvimentos de vulto: a ascensão de Hitler ao poder, na Alemanha, e o início do governo de Franklin Delano Roosevelt, nos Estados Unidos, ocorridos, respectivamente, em janeiro e março de 1933. Pollock reafirma, então, que a profundidade da grande depressão deve ser atribuída à gravidade do conflito entre as forças produtivas e as relações de produção e, mais uma vez, destaca as transformações estruturais do capitalismo que estão por trás deste conflito, essencialmente a centralização do capital. Avançando em relação ao artigo anterior, contudo, ele argumenta que as tentativas de adaptação das relações de produção às forças produtivas já estão em curso e que elas parecem requerer uma forma política específica. Um aprofundamento da análise sobre a escassa capacidade de resistência dos trabalhadores, aliado a uma avaliação explícita tanto do New Deal, iniciado por Roosevelt, quanto das medidas tomadas na Alemanha, fundamentam esse novo diagnóstico. Pollock descreve o ineditismo dos acontecimentos da seguinte maneira:

Uma das características determinantes da atual situação social é que o conflito entre forças produtivas e relações de produção atingiu uma violência até então desconhecida. Nunca com tanto ímpeto as diversas forças que podem ser colocadas a serviço das necessidades humanas chocaram-se com os limites que são impostos a elas pela forma das relações humanas fundadas na divisão do trabalho. Qualitativamente, este processo não apresenta nada de novo: a longa série de crises econômicas é uma expressão do fato de que, em intervalos mais ou menos breves, demonstrase a incapacidade da atual forma econômica de colocar as forças que ela mesmo desenvolveu a serviço de todos os membros da sociedade. A descrição, contudo, que hoje se oferece diferencia-se quantitativamente do processo "normal" de adaptação das fases precedentes; ela é expressão da situação atual, na qual as forças produtivas, em cada setor, agitam com uma violência sem precedentes os grilhões representados pelas relações de produção, especialmente na medida em que elas estão encarnadas em relações de propriedade determinadas (Pollock, 1933/1973, pp.153-154).

A mencionada descrição do processo de adaptação abrange a nacionalização de empresas e de setores econômicos inteiros e o aprofundamento da separação entre a propriedade e o controle do capital, com uma limitação crescente do poder 
do proprietário individual dos meios de produção de decidir autocraticamente o modo e a direção da própria atividade econômica (Pollock, 1933/1973, pp.162-167). Pollock destaca também os processos de fusão e cartelização promovidos pelo Estado em diversos setores, particularmente na Alemanha, na Itália e nos Estados Unidos. $\mathrm{E}$ as intervenções sobre o comércio exterior, incluindo medidas protecionistas e administração da taxa de câmbio, adquirem também centralidade. Na sua avaliação, “[o]s muitos planos de intervenção conjuntural através de diversas medidas de política monetária e creditícia ou através de políticas estatais de geração de emprego encontraram na política rooseveltiana a aplicação mais radical que a história do capitalismo já conheceu" (idem, p.165).

Tais transformações não representam, entretanto, a superação do modo de produção capitalista. Na realidade, elas representam a sua persistência:

O fato de que as intervenções realizadas sobre as relações de produção, a fim de adaptá-las às forças produtivas, assumiram nos últimos anos uma amplitude que até então seria impensável em tempos de paz é sintomático do poder das tensões que hoje se produzem no interior do sistema capitalista. Como em outras regiões, também aqui na Alemanha o capitalismo tem demonstrado uma insuspeitada capacidade de resistência e adaptação (Pollock, 1933/1973, pp.162-163).

Essa “insuspeitada capacidade de resistência e adaptação” do capitalismo pode ser, em parte, atribuída à relativa fraqueza do seu principal adversário: a classe trabalhadora, que tem que arcar com os custos da adaptação. Na divisão do trabalho no interior do Instituto de Pesquisa Social, o estudo sobre os trabalhadores ficou a cargo de outras pessoas e o assunto ocupa um espaço secundário nos trabalhos de Pollock. Contudo, neste artigo de 1933, ele desempenha um papel fundamental para o argumento e é mencionado com mais destaque. Pollock descreve, sobretudo, o processo de diferenciação ocorrido no interior da classe operária, que resultou no surgimento de uma "aristocracia operária", algo que já havia sido apontado por Vladimir Lênin. Tal diferenciação implicava um enfraquecimento da resistência que poderia ser oposta pelos trabalhadores (Pollock, 1933/1973, pp.170-172). Nas palavras dele:

Essa capacidade de resistência, conforme a experiência ensina, foi no passado notavelmente superestimada; o peso alterado da classe operária no processo econômico, o revolucionamento ocorrido na técnica militar e o aperfeiçoamento do condicionamento das massas induzem a pensar que uma insurreição só seria possível, em um futuro não muito longínquo, como consequência de catástrofes gravíssimas (idem, p.168).

Essa análise leva Pollock a alterar explicitamente sua opinião anterior de que uma economia planejada capitalista não seria tolerada pelos proprietários dos meios de produção, devido a sua degradação a mera condição de rentiers. Segundo ele, 
“em face da possibilidade de domínio das massas que se delineou neste ínterim, [essa opinião] não pode mais ser considerada uma objeção válida” (Pollock, 1933/1973, p.167, n. 50). Em outras palavras, a subjugação dos trabalhadores permite que os proprietários percam a sua função social, mas ao mesmo tempo mantenham a sua posição dominante.

Vale ressalvar que, em 1933, Pollock não argumenta que a passagem para a economia planejada capitalista já se realizou, embora tenham avançado as intervenções sobre as relações de produção. Mas, considerando esses desenvolvimentos recentes associados a Hitler e Roosevelt, ele considera essa passagem plausível. ${ }^{10}$ Ao afirmar que os conflitos de interesse internos à classe dominante são os principais obstáculos que restaram, ele conclui: "se as dificuldades do sistema capitalista aprofundaremse ainda mais, até estes obstáculos [à reorganização planejada da economia] serão presumivelmente superados - ainda que isso requeira duríssimas lutas - para salvar o sistema" (Pollock, 1933/1973, p.167).

Finalmente, a análise das transformações em curso permite Pollock dar um último passo e formular uma tese que será complementada por Herbert Marcuse e definirá a maior parte das análises dos membros do Instituto de Pesquisa Social acerca do nazismo. Trata-se da tese de que tais intervenções realizadas nas relações de produção, durante a fase monopolista do capitalismo, requerem um governo autoritário:

[u]m tal remodelamento dos métodos econômicos é necessariamente acompanhado por uma transformação total da organização política da sociedade. Os eventos dos últimos anos mostraram quais são as características peculiares da forma política correspondente ao capitalismo monopolista (Pollock, 1933/1973, pp.167). ${ }^{11}$

E, mais adiante, ele complementa: “[o] parlamentarismo era pouco adaptado a esses propósitos na medida em que correspondia a uma menor concentração do poder econômico" (idem, p.172). Pollock formulava assim, a partir das tendências observáveis no desenvolvimento recente do capitalismo, uma explicação convincente para o abandono paralelo dos liberalismos político e econômico, que caracterizou a década de $1930 .{ }^{12}$

10 Enquanto, por outro lado, torna-se crescentemente questionável a possibilidade de se estabelecer uma economia planejada socialista. Ver, adiante, nota 17, sobre o lugar ambíguo ocupado pela União Soviética no diagnóstico de Pollock.

11 Dubiel busca contextualizar essa declaração: “É evidente quais eram esses 'eventos', aos quais Pollock alude: von Papen era chanceler desde maio de 1932 e suas medidas pró-nazismo são bem conhecidas. Precisamos aqui apenas mencionar sua suspensão do decreto de Brüning que proibia a SA. Seguiu-se a isso o gabinete de transição de Schleicher e, em janeiro de 1933, Hitler tornouse chanceler. Em fevereiro, foi a vez do Decreto para a Proteção do Povo e do Estado (...), que suspendeu todos os direitos constitucionais. Finalmente, em março, veio a 'lei da concessão de poder', que aboliu a divisão de poderes ao estender funções legislativas ao gabinete” (Dubiel, 1978/1985, p.22).

12 Ver, nesse sentido, Hobsbawm (1994, cap.4, pp.109-141). 


\section{A primazia da política no capitalismo de Estado}

Como se pôde perceber, se a relação entre planejamento econômico e emancipação já era ambígua, para Pollock, em 1932, no seu artigo do ano seguinte ela torna-se ainda mais problemática. Através da análise da reduzida capacidade de resistência da classe trabalhadora e da crescente inclinação dos capitalistas a aceitarem (para não dizer, promoverem) a adaptação das relações de produção às forças produtivas, as possibilidades de uma reorganização planejada da economia que colocasse em questão a ordem social capitalista e abrisse o caminho à emancipação pareciam, na leitura de Pollock, muito restritas. Mas, apesar disso, ainda é possível identificar um resquício dessa esperança no texto de 1933, quando ele afirma o seguinte: "Se (...) surgir novamente (como é provável que ocorra) grandes dificuldades econômicas e sociais, terá sido alcançado então o ponto no qual as relações de produção, convertidas novamente em grilhões e não alteráveis ulteriormente, não resistirão mais à pressão das forças produtivas” (Pollock, 1933/1973, p.168)

No entanto, entre 1933 e 1941, ano em que Pollock publicou seu artigo mais conhecido, "Capitalismo de Estado: possibilidades e limites", seu diagnóstico de época passou por um outro deslocamento, que buscarei detalhar nesta seção. Ele está relacionado, em parte, à consolidação do nazismo na Alemanha que, conforme mencionado, já havia influenciado o artigo de 1933. É necessário, porém, destacar outros dois elementos essenciais para a alteração do seu diagnóstico: a crescente atitude crítica que os membros do Instituto de Pesquisa Social, em geral, e Pollock, em particular, assumiram em relação à União Soviética; e a avaliação do autor acerca dos desdobramentos da teoria econômica, ao longo da década de 1930, em especial acerca do debate sobre o que se convencionou chamar de "cálculo socialista".

A avaliação sobre a situação da União Soviética era, naturalmente, definidora para aqueles que pretendiam levar adiante o legado de Marx e que assumiam uma postura crítica em relação à realidade capitalista. Durante a maior parte da década de 1930, os membros do Instituto recusaram-se a criticar publicamente os desenvolvimentos soviéticos, provavelmente como consequência de preocupações táticas (Dubiel, 1978/1985, pp.15-20). Entretanto, análises da correspondência trocada entre eles têm revelado que a simpatia cautelosa que eles nutriam em relação à União Soviética no começo da década de 1930 foi sendo substituída por uma atitude crescentemente crítica, culminando na rejeição completa e na aproximação sugerida entre a realidade soviética e o nazismo (idem, pp.41-44).

Os expurgos realizados por Josef Stalin a partir do final de 1934, e que se tornaram conhecidos no mundo todo a partir de 1936 e 1937, estão provavelmente entre os eventos mais significativos para essa mudança de avaliação. Neste período, vários membros da oposição interna bolchevique, com quem Pollock entrou em contato 
em sua passagem pela União Soviética em 1927, foram condenados e executados. Entre eles, o próprio David Ryazanov, que havia sido o principal contato de Pollock naquela ocasião. Os expurgos seriam, ainda, dramaticamente complementados pelo pacto firmado entre Stalin e Hitler, em 1939. Como reação a estes desdobramentos, uma parte significativa da intelectualidade socialista da Europa ocidental passou a rejeitar a experiência soviética. Em uma carta de setembro de 1937, o próprio Pollock referiu-se a Stalin como um “gangster” (Dubiel, 1978/1985, p.41).

Parece claro que tais eventos estão por trás da revisão sobre a concepção de emancipação realizada pelos membros do Instituto de Pesquisa Social. Max Horkheimer e Herbert Marcuse, principalmente, esforçaram-se para argumentar que uma passagem para uma economia planejada não implica a emancipação (Dubiel, 1978/1985, pp.42-44, 66-67). Tal argumento já havia sido antecipado pela hesitação com que Pollock, em 1932 e 1933, abordava o vínculo entre planejamento e socialismo. $\mathrm{E}$, por sua vez, essa revisão repercutiria no próprio diagnóstico posterior de Pollock, uma vez que conferia um papel à democracia na concepção de emancipação. A seguinte passagem do artigo “Filosofia e Teoria Crítica”, publicado por Horkheimer em 1937, é reveladora:

A passagem da produção industrial ao controle estatal é um fato histórico cujo significado terá ainda que ser analisado pela teoria crítica. Se se trata de uma socialização autêntica, até que ponto se desenvolverá, portanto, um princípio mais elevado não depende apenas da alteração de certas relações de propriedade, do aumento da produtividade nas novas formas de cooperação social, mas também da essência do desenvolvimento da sociedade, na qual ocorre. (...) Pertence ao conteúdo do conceito de socialização o problema de como e o que será produzido, se existirão grupos relativamente bem demarcados e com interesses especiais, e se diferenças sociais serão mantidas ou mesmo ampliadas. Além disso, pertence ao conteúdo desse conceito o relacionamento ativo do indivíduo com o governo, a relação entre todos os atos administrativos decisivos, que dizem respeito aos indivíduos, e o seu próprio saber e vontade, a dependência de todas as situações de decisão coletiva domináveis pelo homem, em poucas palavras, o grau de desenvolvimento dos elementos essenciais, da democracia real e da associação (Horkheimer, 1937/ 1975, p.167).

Reagindo a essa reformulação do conteúdo da emancipação, Pollock passa a diferenciar explicitamente planejamento e socialismo. No seu artigo de 1941 sobre o capitalismo de Estado, ele comenta que os autores da extensa literatura sobre planejamento socialista "não deram a devida atenção ao fato de que planejamento está longe de ser idêntico a socialismo. Esta é a razão pela qual seu trabalho, por mais importante que seja, parece ser uma contribuição maior à teoria do capitalismo de Estado" (Pollock, 1941a, pp.212, n. 1). Ele substitui, então, neste artigo, a alternativa entre economia planejada capitalista e economia planejada socialista, que formulara em 1932, pela alternativa entre as formas autoritária e democrática do capitalismo de Estado (idem, p.201-202). O que não significa dizer que a emancipação 
foi simplesmente renomeada, de socialismo para democracia. Na realidade, tal deslocamento de seu diagnóstico de época representa um questionamento mais profundo da possibilidade de qualquer forma de emancipação, inclusive porque ele deixa em aberto se a forma democrática do capitalismo de Estado é sequer possível. Ele argumenta que ela é teoricamente concebível, mas que a experiência dos últimos anos apontava muito mais claramente para a forma autoritária do capitalismo de Estado. Em um artigo de 1940, em que ele usa a expressão "economia em preparação para guerra" (preparedness economy) para denominar o que, em 1941, ele chamará de capitalismo de Estado, Pollock faz a seguinte afirmação:

Os últimos desenvolvimentos na França e na Inglaterra parecem sugerir uma perspectiva sombria: enquanto na Alemanha e na Itália, o fascismo criou a economia em preparação para guerra, na Inglaterra e na França, as tendências inerentes a uma economia em preparação para guerra lançam as bases para alguma forma de fascismo (Pollock, 1940, p.324).

Isso indica que a formulação do diagnóstico do capitalismo de Estado não foi senão uma atualização da tese, mencionada acima, de que o autoritarismo é a forma política adequada ao capitalismo monopolista. Entretanto, ainda que ele dê todas as indicações de que também considera o autoritarismo a forma política adequada ao capitalismo de Estado, a sua admissão da possibilidade de uma forma democrática provou-se importante para que futuras gerações da Teoria Crítica pudessem atualizar o conteúdo do conceito de emancipação. Quando o fizeram, elas responderam a um apelo que ele mesmo realizou no final do seu artigo sobre o capitalismo de Estado: "É vital para todos que acreditam no valor da democracia que se investigue se o capitalismo de Estado pode ser submetido a um controle democrático" (Pollock, 1941a, p.224). Além disso, ele acrescenta que os “principais obstáculos à forma democrática do capitalismo de Estado são de natureza política e só podem ser superados politicamente" (idem, p.225).

Voltarei a essa questão adiante, após descrever o que ele entende por capitalismo de Estado. Por ora, retorno ao outro elemento que influenciou o deslocamento do seu diagnóstico durante a década de 1930: os desenvolvimentos da teoria econômica. Estimulados pela concepção teórica que ficou conhecida por “materialismo interdisciplinar”, formulada por Horkheimer no início da década de 1930, Pollock, Mandelbaum e Meyer dedicaram-se ao estudo da teoria econômica da sua época. Tal estudo não se restringia à avaliação abrangente das teorias sobre planejamento econômico, já mencionada, ainda que esta tivesse centralidade. Em seus artigos, Pollock mostra que estava particularmente atualizado com o que se produzia no campo da economia.

Uma influência digna de nota é a dos economistas da chamada "Escola de Kiel” que, liderados por Adolf Löwe, dedicaram-se ao estudo das teorias dos ciclos 
econômicos. Trabalhos de Löwe e de Hans Neisser, especialmente, são mencionados frequentemente por Pollock para sustentar seus argumentos. ${ }^{13}$ Vale também mencionar que ele recorre por diversas vezes a fontes de informação econômica que eram uma novidade típica do período entreguerras: os boletins de estatística. Inaugurava-se, nesta época, a coleta e divulgação dos dados sobre as economias nacionais, que hoje fazem parte do cotidiano de todas economias capitalistas. Documentos deste gênero, publicados pelo Instituto de Pesquisas sobre o Ciclo Econômico, dirigido por Ernst Wagemann, pelo Instituto sobre a Economia Mundial de Kiel, ao qual estava ligado Löwe, e pela Liga das Nações, são utilizados recorrentemente por Pollock. ${ }^{14}$ Outro exemplo significativo da sua relação com a teoria econômica da época é o ensaioresenha que ele publicou, em co-autoria com Mandelbaum, sobre o influente livro de Keynes, Teoria Geral do Emprego, do Juro e da Moeda (1936/1997). Publicado no mesmo ano em que foi lançado o livro resenhado, 1936, o ensaio de Pollock e Mandelbaum (1936/1973) reconstrói detalhadamente a teoria formulada por Keynes e lhe dirige críticas influenciadas, em maior ou menor grau, por Marx. Este ensaio é um exemplo muito interessante da forma de apropriação crítica da teoria econômica convencional que os membros do Instituto de Pesquisa Social buscavam empreender. ${ }^{15}$

De qualquer maneira, o debate sobre o planejamento e, especialmente, aquele que envolvia a questão do chamado "cálculo socialista", isto é, a possibilidade de calcular adequadamente os custos de produção na ausência de um mercado, foi central para o argumento de Pollock. Já no artigo de 1932, ele relata várias controvérsias oriundas dessa literatura, posicionando-se sempre no sentido de que o planejamento seria possível (Pollock, 1932/1973, pp.101-107). Contudo, ele afirma que a prova de que uma economia planejada seria mais produtiva do que o sistema econômico baseado no mercado "só pode ser dada, em última análise, na prática" (idem, p.101). E, adiante, ele ressalva que, embora os pressupostos econômicos de uma economia planejada estejam aparentemente presentes, "o nível atual da teoria

13 Vale observar que, de acordo com Rolf Wiggershaus (1986/1994, p.95), Löwe era amigo de infância de Max Horkheimer e, ao se transferir em 1931 para Frankfurt, passou a frequentar um grupo de discussões integrado por, entre outros, Theodor W. Adorno, Karl Mannheim e pelo próprio Pollock, além de Horkheimer.

14 Sobre a influência de tais boletins estatísticos durante o República de Weimar, ver J. Adam Tooze (1999).

15 Devido à perseguição nazista, vários artigos publicados na revista do Instituto de Pesquisa Social, Zeitschrift für Sozialforschung, recorriam a pseudônimos. Por essa razão, há ainda incerteza em relação à autoria de alguns deles. Os artigos "Artakie und Planwirtschaft" e "Keynes' Revision der liberalistischen Nationalökonomie", que aparecerem respectivamente sob o pseudônimo de Kurt Baumann e Erich Baumann, são atribuídos normalmente a Mandelbaum. Giacomo Marramao, contudo, inclui ambos em sua coletânea dos textos de Pollock, indicando que eles foram escritos em colaboração por Pollock e Mandelbaum. Como não foram realizadas justificativas para tais atribuições de autoria, é impossível chegar a uma conclusão definitiva. No entanto, há uma carta escrita por Horkheimer, para Theodor W. Adorno, datada de 14 de novembro de 1936, em que ele afirma: "será publicada uma crítica do livro mais recente de Keynes, escrita por Mandelbaum e revisada por Pollock" (Horkheimer, 1995/2007, p.78). 
sobre o planejamento não permite que se delineie um modelo detalhado da nova economia" (idem, p.107).

Essa atitude muda significativamente no seu artigo de 1941 sobre o capitalismo de Estado, no qual ele busca, aliás, delinear justamente tal modelo da nova economia. Mencionando uma literatura posterior, ele afirma que “[a] discussão sobre planejamento chegou a um ponto em que parece que os argumentos contrários à viabilidade técnica de um plano geral deste tipo podem ser refutados" (Pollock, 1941a, p.204). E, em uma outra passagem, em que cita um livro organizado por Friedrich von Hayek, que compila as críticas à possibilidade do planejamento, e afirma que tal argumento foi refutado por Oskar Lange, ele reforça: "Pensamos que qualquer pessoa que estudar seriamente a literatura moderna sobre planejamento deve chegar à conclusão de que, quaisquer que forem suas objeções às consequências sociais do planejamento, estes argumentos contrários a sua eficiência econômica não se sustentam mais" (idem, p.216). As obras mencionadas de Hayek e Lange estão, precisamente, entre os loci clássicos do debate sobre o "cálculo socialista".

É importante ressalvar, de qualquer forma, que não se trata de assumir a posição idealista segundo a qual o desenvolvimento da literatura acerca do planejamento seria um pressuposto à realização de uma economia planejada, na prática. Na realidade, Pollock deixa claro que o avanço da discussão teórica sobre o assunto acompanha transformações em curso do próprio capitalismo, que the conferem, por assim dizer, uma base material: “As experiências das grandes corporações industriais e de distribuição, assim como as dos cartéis, fornecem um complemento muito valioso à literatura especial sobre planejamento" (Pollock, 1941a, p.215). Tal complemento não é senão aquilo que, nos artigos do começo da década de 1930, ele considerava os pressupostos econômicos para uma reorganização planejada da economia. A resolução do debate sobre o planejamento significava apenas que tal reorganização poderia ser mais bem auxiliada pela teoria.

O diagnóstico do capitalismo de Estado resulta, assim, precisamente de um aprofundamento das tendências que Pollock já identificava desde o começo da década de 1930. O fato de que a literatura sobre o planejamento atingiu um nível que tornou insustentável as objeções a ele é apenas um exemplo. Outro é o fato de que a inadequação do mecanismo de mercado para alocar recursos, resultante da concentração de capital, tornou-se mais patente. Enquanto antes ela se manifestava no paradoxo da pobreza em meio à abundância, agora tal inadequação aponta para a possibilidade de uma “desintegração completa da estrutura social” (Pollock, 1941a, p.202). Ainda, Pollock já afirmava desde 1932 que a propriedade privada em muitos casos havia sido reduzida a "uma pretensão mais ou menos segura ao recebimento de uma renda” (Pollock, 1932/1973, p.107), como consequência da separação entre propriedade e controle do capital. Em 1941, por sua vez, ele pode afirmar que o 
capitalismo de Estado deve "transformar o capitalista em um mero rentier cuja renda é fixada por decisão governamental desde que seus investimentos sejam bemsucedidos, e que não tem direito de retirar seu capital se os 'juros' não forem pagos” (Pollock, 1941a, p.209). Radicaliza-se, desse modo, a separação entre propriedade e controle.

Nesse sentido, Pollock argumenta que o capitalismo de Estado não aparece, de repente, com a ascensão do nazismo ou com a implementação do New Deal. Ele remonta a processos históricos anteriores. "Desenvolvimentos sociais e econômicos ocorridos na Europa desde o fim da Primeira Guerra Mundial são interpretados como processos de transição na transformação do capitalismo privado em capitalismo de Estado" (Pollock, 1941a, p.200). A reorganização econômica que estava latente, na sua interpretação, desde o começo da década de 1930 parecia finalmente ter se realizado. O sistema econômico e social resultante, o capitalismo de Estado, é concebido como um tipo ideal que combina elementos visíveis na Europa, na União Soviética e nos Estados Unidos (idem, ibidem). Ele tem o cuidado de deixar em aberto, no entanto, se tal combinação se completaria na prática.

No que consiste, então, esse tipo ideal? Ao justificar a escolha do conceito, Pollock menciona quatro características que definem a nova ordem: é a sucessora do capitalismo privado; o Estado assume funções importantes que cabiam aos capitalistas; o lucro ainda desempenha um papel significativo; e não se trata de socialismo (Pollock, 1941a, p.201). A descrição que ele fornece do funcionamento do capitalismo de Estado revela claramente que as fontes de inspiração principal são o nazismo e a União Soviética. A centralização e a racionalização da produção realizada na Alemanha é complementada, na formulação do tipo ideal, pelo sistema de distribuição criado na economia soviética (idem, p.206, nn. 1-2; 208, n. 2; e 211, n. 1$).{ }^{16}$

O seu elemento mais importante é a descrição dos instrumentos utilizados pelo Estado para alocar os recursos e coordenar a produção e a distribuição. Dentre

16 É importante ressalvar que a União Soviética ocupa um papel ambíguo na obra de Pollock. Conforme argumentei acima, a avaliação sobre a experiência soviética foi fundamental para orientar a concepção de emancipação adotada pelo autor. Mas, por outro lado, a trajetória distinta da economia soviética impediu que ela adquirisse centralidade na formulação do diagnóstico de época, ainda que sirva como referência. Assim, em 1932, Pollock argumenta que a experiência soviética não pode ser usada para discutir a superioridade de uma reorganização planejada da economia, em relação ao capitalismo privado, dada a singularidade da situação russa. Em outras palavras, uma reorganização planejada das economias relativamente mais desenvolvidas seria, segundo ele, algo qualitativamente distinto do processo verificado na União Soviética (Pollock, 1932/1973, p.107, n. 24). Em 1941, a particularidade russa é novamente enfatizada por Pollock, agora por outros motivos: "A situação é diferente na Rússia soviética onde os direitos adquiridos foram completamente eliminados. Como na Rússia a propriedade dos meios de produção mudou de mãos completamente, dos proprietários privados para o Estado, e não existe mais nem na forma reduzida e modificada discutida acima, é de certo modo duvidoso se o nosso modelo de capitalismo de Estado adequa-se à União Soviética na sua fase atual” (Pollock, 1941a, p.221, n. 1). 
esses instrumentos, Pollock atribui um papel importante ao que denomina "pseudomercado", que pode ser compreendido como a utilização das antigas instituições do capitalismo privado, particularmente o sistema de preços e a busca do lucro, de forma subordinada e instrumental ao planejamento centralizado (Pollock, 1941a, p.201, 204-206). Assim, segundo ele, como os preços são administrados, a relação entre, de um lado, preços e custos de produção e, de outro, oferta e demanda é desfeita sempre que ela interfira com os objetivos do plano (ressalvando, naturalmente, que tal relação é mantida no agregado, o que decorre necessariamente da interdependência da circulação econômica). O lucro, por sua vez, segue desempenhando o papel de incentivo, mas igualmente é subordinado às necessidades do planejamento. Nesse sentido, Pollock argumenta que "todas as instituições e conceitos básicos do capitalismo mudaram de função; a interferência do Estado na estrutura da velha ordem econômica, devido a sua abrangência e intensidade, 'converteu quantidade em qualidade', transformando o capitalismo monopolista em capitalismo de Estado" (Pollock, 1941b, p.445). ${ }^{17}$

Outra característica determinante do capitalismo de Estado, segundo Pollock, é a racionalização completa de todas as atividades estatais e, ao mesmo tempo, a ampliação de tais atividades para "todas as esferas da vida social” (Pollock, 1941a, p.206). Áreas distintas entre si como a condução da guerra, o comportamento em relação à opinião pública e a propaganda estatal, o exercício do poder coercitivo do Estado e a condução do comercio exterior são mencionadas como exemplos de esferas da atividade do Estado que substituíram toda forma de improvisação por uma racionalização integral. O caráter opressor dessa racionalização é ressaltado por Horkheimer, em um prefácio que é dedicado preponderantemente a comentar o diagnóstico de Pollock: "a racionalidade irracional torna-se loucura com método" (Pollock, 1941, p.197).

A tese essencial de Pollock consiste em afirmar que o sentido da passagem do capitalismo privado para o capitalismo de Estado é que "a primazia da política sobre a economia (...) estabelece-se claramente” (Pollock, 1941b, p.453). Em outras palavras: "[a] substituição de meios econômicos por meios políticos como garantia em última instância da reprodução da vida econômica altera o caráter de todo o período histórico. Significa a transição de uma era predominantemente econômica para uma essencialmente política” (Pollock, 1941a, pp.206-207). A realização do

17 Esse é o ponto central da polêmica sobre o diagnóstico do capitalismo de Estado que opôs, no interior do Instituto de Pesquisa Social, Pollock, Horkheimer e Adorno, de um lado, e Marcuse, Franz Neumann e A. R. L. Gurland, de outro. Resumidamente, estes argumentavam que a existência da propriedade privada, do sistema de preços e da busca do lucro determinava a continuidade do capitalismo monopolista, sendo equivocada a interpretação de que este havia sido superado. Pollock reagiria a esta posição afirmando que ela consistia em "tomar fenômenos superficiais pelo seu valor de face" (Pollock, 1941b, p.445), isto é, subestimar o fato de que as mesmas instituições passaram a desempenhar funções qualitativamente distintas. 
capitalismo de Estado representaria a superação da contradição entre forças produtivas e relações de produção, sem que se superasse, ao mesmo tempo, o capitalismo. ${ }^{18}$ O diagnóstico do início da década de 1940 respondia, assim, a uma pergunta que ele havia formulado em 1933: até que ponto as relações de produção poderiam ser adaptadas sem eliminar os pressupostos sobre os quais se fundamenta o sistema capitalista (Pollock, 1933/1973, pp.136, 167-168)? O capitalismo de Estado demonstraria que virtualmente inexistiriam limites para essa adaptação. Os limites econômicos, por assim dizer, do capitalismo privado, representados pela contradição entre forças produtivas e relações de produção, teriam sido superados.

Precavidos que estamos, não podemos encontrar nenhuma força inerentemente econômica, "leis econômicas" de velho ou novo tipo, que poderiam impedir o funcionamento do capitalismo de Estado. O controle governamental da produção e da distribuição fornece os meios para eliminar as causas econômicas das depressões, dos processos destrutivos cumulativos e do desemprego de capital e trabalho. Podemos até mesmo dizer que, sob o capitalismo de Estado, a economia enquanto ciência social perdeu o seu objeto. Problemas econômicos no velho sentido não existem mais, quando a coordenação de todas as atividades econômicas é realizada conscientemente através de um plano e não pelas leis naturais do mercado. Onde antes o economista quebrava a cabeça para resolver o enigma do processo de troca, ele encontra, sob o capitalismo de Estado, meros problemas administrativos (Pollock, 1941a, pp.216-217).

Cabe, então, uma pergunta natural: o capitalismo de Estado implica a estabilização completa da vida social? Se a contradição entre forças produtivas e relações de produção manifestava-se no opressor paradoxo da pobreza em meio à abundância, ao mesmo tempo, ela apontava a possibilidade de uma superação em direção a uma sociedade emancipada. Desse modo, se tal contradição foi superada preservando o capitalismo, cabe questionar se a emancipação foi retirada do horizonte de possibilidades em absoluto. Ou, nas palavras de Pollock: "se o capitalismo de Estado abre um novo caminho à liberdade ou leva a sua perda completa para a grande maioria" (Pollock, 1941a, p.221).

Sua resposta a essa questão é hesitante. Ele busca argumentar que a estabilização econômica promovida pelo capitalismo de Estado não era acompanhada de uma estabilização política paralela. Assim, não é certo que se conseguirá realizar a conciliação política de interesses pressuposta ao planejamento centralizado. E, além disso, como "o capitalismo de Estado na sua forma autoritária é a expressão extrema de uma sociedade antagônica" (Pollock, 1941a, p.219), as dificuldades políticas devem ser ainda mais ampliadas e sua estabilização ainda mais duvidosa. É verdade, contudo, que Pollock afirma que o capitalismo de Estado dispõe dos meios necessários para empreender uma dominação política que combina elementos de consenso e de coerção. Ele menciona o recurso à intensa propaganda e ao terror

18 Ver, nesse sentido, Nobre (1998, pp.35-36). 
organizado e racionalizado, por um lado, e a garantia do pleno emprego e de um padrão de vida adequado para grupos sociais politicamente importantes, por outro. Mas não é possível afirmar se há limites a tal dominação política.

Todas essas considerações estão relacionadas à forma totalitária do capitalismo de Estado que, na realidade, é a forma que orienta decisivamente a formulação do diagnóstico. Mas, conforme já mencionei, Pollock concebe também a possibilidade teórica de uma forma democrática, em que o Estado seria controlado pelo povo (Pollock, 1941a, p.202). "Ela seria baseada em instituições que impediriam a burocracia de transformar a sua posição administrativa em um instrumento de poder, lançando as bases, assim, para transformar o sistema democrático em um sistema totalitário" (idem, ibidem). A questão crucial é, então, se essa forma democrática, acerca da qual, nas palavras dele, "a experiência histórica nos dá poucas pistas" (idem, p.200), pode ser realizada na prática. E, além disso, se há alguma tendência inscrita no capitalismo de Estado que aponte na direção da realização de sua forma democrática. Pollock apenas formula tais questões, sem as responder. Uma das importâncias do seu diagnóstico é justamente reconhecer o caráter problemático da emancipação, sob o capitalismo de Estado, apontando ao mesmo tempo a direção que deve ser trilhada para reformulá-la e recolocá-la como possibilidade histórica. Ele deixaria essa tarefa às gerações posteriores da teoria crítica. ${ }^{19}$

\section{Considerações finais}

A primeira pergunta que se costuma dirigir ao diagnóstico de época de Pollock, como, de resto, a qualquer diagnóstico, é se ele se mantém atual. ${ }^{20}$ É possível argumentar que, em muitos aspectos, o capitalismo do início do século XXI ainda é caracterizado pela primazia da política sobre a economia. Mas a avalanche ideológica neoliberal, em curso há cerca de quatro décadas, que insiste na centralidade do mercado, torna essa atualização contra-intuitiva. E interpretar a realidade contemporânea indo além do valor de face dos fenômenos superficiais, para usar a expressão de Pollock, e analisando detalhadamente a interpenetração entre o político e o econômico que caracteriza o capitalismo na sua fase atual requereria um outro artigo.

19 É notável a semelhança do diagnóstico de Pollock, neste ponto, com a análise realizada por Karl Polanyi no livro A grande transformação (1944/2001), publicado em 1944. Polanyi também avaliava estar em curso uma politização da economia e descrevia o fascismo como "uma reforma da economia de mercado alcançada através da exterminação de todas as instituições democráticas" (Polanyi, 1944/2001, p.245). O desafio, para ele, era o mesmo identificado por Pollock: conciliar a politização da economia com a democracia. Ver, nesse sentido, Polanyi (1944/2001, esp. cap.21, pp.257-265). Marcos Nobre chamou a minha atenção para este paralelo.

20 Nobre discute como Adorno e Jürgen Habermas buscaram compreender, cada um à sua maneira, o capitalismo do pós-guerra partindo da obra de Pollock. Os seus trabalhos podem ser compreendidos, por isso, como formas distintas de atualizar o diagnóstico do capitalismo de Estado. Ver, nesse sentido, Nobre (1998, cap.1, pp.21-58). 
Não há dúvida, de qualquer maneira, que recuperar o pensamento de Pollock contribui para evitar o recurso a distinções simplificadoras, como intervenção estatal versus livre mercado, cujo poder explicativo é no mínimo questionável. Escapar a essa redução ideológica requer que se reconheça a interdependência estrutural entre política e economia que caracteriza o capitalismo contemporâneo. Dessa maneira, a comparação recorrente entre a crise atual e a de 1929 poderia ser recolocada em outros termos, explicitando suas diferenças, sem desconsiderar, contudo, a gravidade dos acontecimentos recentes. De modo geral, o diagnóstico do capitalismo de Estado permite melhor apreender os atuais limites da reprodução do capitalismo e os determinantes contemporâneos das crises que continuam, hoje como ontem, afetando o sistema.

\section{Referências $^{21}$}

\section{a) Textos de Friedrich Pollock}

Pollock, F. (1929/1973). "Gli esperimenti di pianificazione economica in Unione Sovietica: osservazioni critiche sul comunismo di Guerra e la NEP" In: Teoria e prassi dell'economia di piano: antologia degli scritti (1928-1941). Organização de Giacomo Marramao. Bari: De Donato, pp.233-270.

(1932/1973). "La situazione attuale del capitalismo e le prospettive di un riordinamento pianificato dell'economia". In: Teoria e prassi dell'economia di piano: antologia degli scritti (1928-1941). Organização de Giacomo Marramao. Bari: De Donato, pp.85-108.

(1933/1973). "Osservazioni sulla crisi economica". In: Teoria e prassi dell'economia di piano: antologia degli scritti (1928-1941). Organização de Giacomo Marramao. Bari: De Donato, pp.135-172.

(1940). Influences of preparedness on Western European economic life. The American Economic Review, 30(1), parte 2, março, pp.317-325.

. (1941a). State capitalism: its possibilities and limitations. Studies in Philosophy and Social Science, IX(2), Nova York, The Institute of Social Research, pp.200-225. [republicado em Arato, A., Gebhardt, E. (orgs.) (1982). The essential Frankfurt School reader. Nova York: Continuum, pp.71-94].

(1941b). Is National Socialism a new order? Studies in Philosophy and Social Science, IX(3), Nova York, The Institute of Social Research, pp.440-455.

(1956/1957). The economic and social consequences of automation.

Translated by W. O. Henderson e W. H. Chaloner. Oxford: Basil Blackwell.

Pollock, F. e Mandelbaum, K. (1936/1973). "La revisione keynesiana del liberalismo economico". In: Teoria e prassi dell'economia di piano: antologia degli scritti (1928-1941). Organização de Giacomo Marramao. Bari: De Donato, pp.173-198.

21 Quando são indicadas duas datas, a primeira refere-se à primeira publicação. 


\section{b) Referências secundárias}

Abromeit, J. (2011). Max Horkheimer and the foundations of the Frankfurt School. Nova York: Cambridge University Press.

Brenner, R.; Glick, M. (1991). The regulation approach: theory and history. New Left Review, 188, julho/agosto, pp.45-119. Recuperado de: [https://newleftreview. org/l/188/robert-brenner-mark-glick-the-regulation-approach-theory-andhistory]. Acesso em 17 set. 2017.

Campani, C. (1992). Pianificazioni e teoria critica: l'opera de Friedrich Pollock dal 1923 al 1943. Liguori Editore.

Dahms, Harry F. (2000). "The early Frankfurt School critique of capitalism: critical theory between Pollock's 'state capitalism' and the critique of instrumental reason". In: Koslowski, P. (org.). The theory of capitalism in the german economic tradition: historism, ordo-liberalism, critical theory, solidarism. Heidelberg: Springer, pp.309-361.

Dubiel, H. (1978/1985). Theory and politics: studies in the development of Critical Theory. Translated by Benjamin Gregg. Cambridge, Mass.: MIT Press.

Gangl, M. (2016). “The controversy over Friedrich Pollock's state capitalism”. History of the Human Sciences, 29(2), pp.23-41. Recuperado de: [http://journals. sagepub.com/doi/abs/10.1177/0952695116637296]. Acesso em 17 set. 2017.

Hilferding, R. (1910/1985). O capital financeiro. Tradução de Reinaldo Mestrinel. São Paulo: Nova Cultural (Coleção “Os Economistas”).

Hobsbawm, E. J. (1989). The age of empire (1875-1914). Nova York: Vintage Books. . (1994). The age of extremes: a history of the world, 1914-1991. Nova York: Vintage Books.

Horkheimer, M. (1937/1975). “Filosofia e teoria crítica”. In: Horkheimer, M. et alli. Walter Benjamin, Max Horkheimer, Theodor W. Adorno, Jürgen Habermas. São Paulo: Abril Cultural (Coleção “Os Pensadores”), pp.163-169.

. (1941). Preface. Studies in Philosophy and Social Science, IX(2), Nova York, The Institute of Social Research, pp.195-199.

(1995/2007). A life in letters: selected correspondence. Organizado e traduzido por Manfred Jacobson e Evelyn Jacobson. Nebraska: University of Nebraska Press.

Keynes, J. M. (1926-1919/2004). The end of laissez-faire / The economic consequences of the peace. Nova York: Prometheus Books.

(1936/1997). The general theory of employment, interest, and money. Amherst: Prometheus.

Kindleberger, C. P. (1986). The world in depression, 1929-1939. 2a. ed. Berkeley: University of California Press.

Marramao, G. (1973/1990). “Da crise do 'mercado auto-regulado' ao 'Estado autoritário'. Notas sobre a relação de economia política e ‘teoria crítica””. In: 0 político e as transformações: crítica do capitalismo e ideologias da crise entre os anos vinte e trinta. Tradução Antonio Roberto Bertelli. Belo Horizonte: Oficina de Livros, pp.203-238. 
Nobre, M. (1998). A dialética negativa de Theodor W. Adorno: A ontologia do estado falso. São Paulo: Iluminuras.

Pedroso, G. (2009). Entre o capitalismo de Estado e o Behemoth: o Instituto de Pesquisa Social e o fenômeno do fascismo. Cadernos de Ética e Filosofia Política, 15(2), pp.151-179.

Polanyi, K. (1944/2001). The great transformation: the political and economic origins of our time. Boston: Beacon Press.

Postone, M. (1993/2003). Time, labor, and social domination: A reinterpretation of Marx's critical theory. New York: Cambridge University Press.

Rugitsky, F. (2008). "Friedrich Pollock: limites e possibilidades”. In: Nobre, M. (org.). Curso livre de teoria crítica. Campinas: Papirus, pp.53-72.

Shaikh, A. (1978). "An introduction to the history of crisis theories". In: U.S. Capitalism in Crisis. Union for Radical Political Economics. New York: Economics Education Project, pp.219-241.

Ten Brink, T. (2015). Economic analysis in critical theory: the impact of Friedrich Pollock's state capitalism concept. Constellations, 22(3), pp.333-340. [http:// onlinelibrary.wiley.com/doi/10.1111/1467-8675.12191/abstract] Acesso em 17 set. 2017.

Tooze, J. A. (1999). Weimar's Statistical Economics: Ernst Wagemann, the Reich's Statistical Office, and the Institute for Business-Cycle Research, 1925-1933. Economic History Review, LII(3), agosto, pp.523-543. [http: / /onlinelibrary.wiley. com/doi/10.1111/1468-0289.00135/abstract]. Acesso em 17 set. 2017.

Wiggershaus, R. (1986/1994). The Frankfurt School: Its history, theories, and political significance. Translated by Michael Robertson. Cambridge: MIT Press. 